\title{
Autoregressive Integrated Moving Average (ARIMA) Model for Exchange Rate (Naira to Dollar)
}

\author{
Nwankwo Steve C \\ Statıstıcs Department, Abia State Polytechnıc, ABA \\ Email: stevenwankwo50@yahoo.com
}

\section{Doi:10.5901/ajis.2014.v3n4p429}

\section{Abstract}

Analysis of exchange rate using ARIMA model, was carried out to help those in charge of the economy who are carried out to help those in charge of the economy who are interested in the strange and irregular trend in the Nigerian exchange rate system, to identify the exchange rate model, estimate the model parameters and predict or forecast the future. In an effort to better understand how exchange rate can be modeled, this work applied ARIMA model to exchange rate (Naira to Dollar) within the periods 1982-2011, through Box-Jenkins methodology an AR(1): order one was generated model is preferred as it was proved through the diagnostic rate of Naira-Dollars based on its potentials for better prediction and computational requirements.

Keywords: Arima model, Exchange rate, diagnostic check.

\section{Introduction}

The exchange rate is a relative price that measures the worth of a domestic currency in terms of another currency. The currency in forecasting the foreign exchange rate or at least predicting the trend correctly is of crucial importance for any future investment.

Exchange rate prediction is one of the demanding applications of modern time series forecasting. The rates are inherently noisy, non-stationary and deterministically chaotic. Box et al (1994)

This characteristics suggest that there is no complete information that could be obtained from the past behavior, of such markets to fully capture the dependency between the future rates and that of the past. Since assumption has it that historical data is the major player in the prediction process, therefore; historical data incorporates all these behaviour. The exchange rate fluctuates and requires a statistical model that can approximately represent the variability. The fluctuation in exchange rate can be examined with a class of structural time series models in order to gain a better understanding of the underlying process and obtain more efficient estimates.

The main objective for this is to adopt a suitable autoregressive model for the analysis of Nigeria exchange rate for Naira versus dollars.

The study is expected to be used by government and policy maker in Nigeria in carrying out their task and it is of significant knowledge embodiment to the economist who are interested in the strange and irregular trend in the Nigeria exchange sector and as such, it is providing the most needed knowledge of different interaction in the Nigeria macroeconomics.

\section{Review of Related Literature}

Akaike (1976) incorporates a money demand function with a partial adjustment mechanism, and finds that reformulated monetary approach can out perform the random walk model in an out-of-sample forecast exercise. Salan (1998) also finds that a monetary model with a large endogenous variables forecasts better than naïve random-walk model. Finn (2010) finds that the simple flexible-price monetary model is not supported by the data while the rational-expectations monetary model is supported and performs as well as the random walk model.

It has long been believed that nominal exchange rate behavior is well described by the naïve random-walk model. This means that there is no systematic economic forces in determining the exchange rates. Messes and Rogoff (1983) showed that none of the structural models (Frankel-Bilson's flexible monetary model, Dorabussh-Frankel's sticky-price monetary model) out perform a simple random-walk on the basis of root-mean-square-error (RMSE) and mean-absolute- 
error criteria for forecast evaluation bias, sampling error, stochastic movement in the true underlining models.

C.B.N (2006) finds that domestic currency appreciation negatively affects domestic shares price for an exportdominant economy and positively affects share prices in an import dominant economy.

Harvey (2001) also found, using a multivariate co-integration technique that an unrestricted monetary model outperforms the random-walk other models in an out-of-sample forecasting experiment for the sterling-dollar exchange rate.

Since the 1970s, models have emphasized the role of exchange rate as asset price. The new work, looking at present value models of exchange rates, highlights the role of expectation in determining exchange rate movements. For many years the standard criterion for judging exchange rate has been, do they beat the random-walk model for forecasting changes in exchange rates? This criterion was popularized by the seminar work of Messes and Rogoff. They found that the empirical exchange rate models of the 1970s that seemed to fit very well in sample tented to have poor out-of-sample fit. The mean-squared error of the models prediction of the exchange rate (using realized values of the explanatory variables) tended to be lower than the mean-squared error of the naïve model that predicts on change in the exchange rate.

Mark's (1995), found that empirical exchange rate models were helpful in predicting exchange rates at long horizons. Subsequent works has cast doubt on whether exchange rates can be forecast at long horizons, so there is a weak consensus that the models are not very helpful in forecasting. It is worth noting that there is a contingent that believes that non-linear models have forecasting power.

In the light of the above this article tends to determine an ARIMA model for the Naira to US dollar exchange rate.

\section{Methodology}

The general autoregressive integrated moving average (ARIMA) model introduction by Box and Jenkins (1976) includes auto-regressive as well as moving average parameters and explicitly includes differencing in the formulation of the model. Specifically, the three types of parameters in the model are: The autoregressive parameter $(P)$, the number of differencing passes (d), and moving average parameters (q). In the notation introduced by Box and Jenkins, the models are summarized as ARIMA $(p, d, q)$.

The ARIMA model, although a non stationary process exhibits homogeneity with respect to the class of series can occur in many ways. They could have non constant mean $\mu$, time varying second moments such as on constant variance $\delta^{2}$, or have both of these properties.

Models useful for representing such behaviours can be obtained by supposing a suitable difference of the process in order to be stationary.

Fortunately, there are models that can be constructed from a single realization to describe this time dependent phenomenon. Two such models that are very useful is modeling non. Stationary in mean are the deterministic trend models. The class of ARIMA models derives its usefulness from the varieties of forecasting situations trend models, exponential smoothing, random work models and auto regression can also be shown to be special cases of ARIMA models.

The Box-Jankins ARIMA models has gained great popularity and are based on the idea that a time series in which successive values are highly dependent can be regarded as being generated from a series of independent shocks. Modeling such series lead to the class of auto regressive integrated moving average ARIMA model.

\section{The General Arima Model}

The general ARIMA model introduced by Box and Jenkins includes Autoregressive as well as moving average parameters. Specifically, the two types of parameter in the model are; the auto regressive parameter ( $p$ ), and the moving average parameter (q). In the notation introduced by the Box and Jenkins, the models are summarized as ARIMA (p,d,q). The general form of the ARIMA $(P, Q)$ process is of the form:

$$
\begin{aligned}
& X_{t}: \mu+\sum \emptyset_{1} X_{t-1}+\sum \theta_{j e t-j}+e_{t} \\
& \text { ARIMA (1,1): } X_{t}: \mu+\emptyset_{1} X_{t-1}+\theta, e_{t-1}+e_{t} \\
& \text { ARIMA (2,2): } X_{t}: \mu+\emptyset_{1} X_{t-1}+\theta, e_{t-1}+\theta_{2} e_{t-2}+e_{t}
\end{aligned}
$$




\section{Analysis}

\subsection{Model Identification}

The model identification according to Box and Jenkins (1994) involved using ACF, PACF, A/C etc the Box and Jenkins ARIMA models can be shown to be optimal and provides a systematic approach to model selection, utilizing all the information contained in the sample autocorrelation (ACF) and partial autocorrelation (PACF) function. The ACF and PACF are adopted here. Using the S. plus application software professional edition version 6.12 Microsoft windows 2002 and the sample autocorrelations (ACF) function. The results are computed using the Data table in the Appendix 2

\subsection{Parameter Estimation}

After the exchange rate of Naira to Dollar assumes autoregressive process of order (1), the parameter was estimated and the value of the coefficient for Naira-Dollar was 1.250374, hence we have the model equation as:

$$
\begin{aligned}
& X_{t}=\emptyset \chi_{t-1}+E_{t} \ldots \ldots \ldots \ldots \ldots \ldots \ldots \text { Exchange rate model }(A R(1)) \\
& \text { Since } \varnothing=1 \text {, exchange rate model is: } \\
& X_{t}=\chi_{t-1}+E_{t} \\
& X_{t}-\emptyset_{X_{t-1}}=E_{t} \\
& (1-1.250374 \beta)=E_{t}
\end{aligned}
$$

\subsection{Diagnostic Checking}

Diagnostic $X_{t}=1.25037 X_{t-1}+E_{t}$ checking procedures are based on the examination of the residuals. The variance is such that if the model is satisfactory, the residuals which are estimates of the error components $E_{t}$ should be approximately normally distributed mean zero.

ARIMA $(1,0,0)$ has the most preferred AKaike (1976) information criterion autocorrelation coefficient statistics of 1964.28496 for Naira-US Dollars data, then the model of order (1) is the most suitable model i.e, AR(1).

\subsection{Summary of Result}

\begin{tabular}{|l|c|}
\hline \multicolumn{1}{|c|}{ Statistic } & Naiar-Dollar \\
\hline Stationary & Non-stationary \\
\hline Model identification & ARIMA $(1,0,0)=\mathrm{AR}(1)$ \\
\hline Model coefficient & 1.250374 \\
\hline Model equation & $\mathrm{X}_{\mathrm{t}}=1.250374 \mathrm{X}_{\mathrm{t}-1}+\mathrm{E}_{\mathrm{t}}$ \\
\hline $\mathrm{A} / \mathrm{c}$ & 1964.28496 \\
\hline
\end{tabular}

\section{Conclusion}

We discovered the following

- Residual is negligible

- Since the model is ARIMA $(1,0,0) ; \operatorname{AR}(1)$ then $\emptyset=1$ i.e. the variance covariance matrix.

- Since the AR is of order 1 , then it is a random walk model.

Foreign exchange has been described as the means of affecting, payments of international transactions with convertible currencies that are generally accepted for the settlement of international trade and other external obligations.

Different models were fitted though $A R(1)$ and $A R(2)$ have the same structural features, the best fit is AR(1) model because it has the most suitable $A / C$. This was achieved through the diagnostic checking which identified it as the best fit. The ARIMA model that I have presented in this paper can provide a better understanding of the underlying system if appropriately parameterized.

Depreciation of exchange rate will make import more expensive than before if the country cannot cutback into import or improve on the volume and value of her export, unfavourable balance of trade occurs, ceteris paribus, this can have serious effect on the balance of payment which may further lead to depreciation of the domestic economy.

Therefore, the government should be able to curtail or limit inflation. Increase savings and make more resources 
available for further productions.

\section{References}

Akaike, H. (1976). Canonical Correlation Analysis of Time Series And The Use of An Information Criterion. Academic Press

Box, G.E.P, and Jenkins, G.M. (1994). Time Series Analysis: Forecasting and Control. $3^{\text {rd }}$ Edition Prentice Hall

Central Bank of Nigeria (2006): Bullion Publication of Central Bank of Nigeria, Volume 30, no. 3, July-Sept.

Finn, D.B. "Structural Time Series Model for the Analysis of exchange Rate of Naira", Department of Statistics, UNAAB, March, 2010.

Harvey, A.C. (2001). Forecasting Time Series Models and the Kalman Filter. Cambridge UK: Cambridge University Press.

Mark, N.C. (1995). "Exchange Rates and Fundamentals: Evidence on long Horizon Predictability", American Economic Review 85 (March): pp. 20118.

Messe, R.A. and Rogoff, K.S. (1983). "Empirical Exchange Rate Models of the Seventies: do they fit out of sample?" Journal of the International Economics 14 (February): Pp. 24

Salan, M.O. (1998). "ARIMA Modeling of Nigeria's Crude Oil Exports", Department of Statistics, Nigeria Education Research and Development Council P.M.N 91, Garki Abuja.

\section{Appendix 1}

\begin{tabular}{|c|c|c|}
\hline Table 1 & Sample & \\
\hline LAG & ACF & PACF \\
\hline 0 & 1.0000 & 0.9922 \\
\hline 1 & 0.9922 & 0.9922 \\
\hline 2 & 0.9840 & -0.0266 \\
\hline 3 & 0.9673 & -0.0009 \\
\hline 4 & 0.9673 & -0.0334 \\
\hline 5 & 0.9585 & -0.0200 \\
\hline 6 & 0.9499 & -0.0136 \\
\hline 7 & 09413 & -0.0051 \\
\hline 8 & 0.9327 & -0.0047 \\
\hline 9 & 0.9241 & -0.0047 \\
\hline 10 & 0.9154 & -0.0067 \\
\hline 11 & 0.9667 & -0.0084 \\
\hline 12 & 0.8980 & 0.0027 \\
\hline 13 & 0.8910 & 0.1021 \\
\hline 14 & 0.8847 & 0.0423 \\
\hline 15 & 0.8785 & -0.0056 \\
\hline 16 & 0.8722 & -0.0078 \\
\hline 17 & 0.8659 & -0.0140 \\
\hline 18 & 0.8659 & -0.0047 \\
\hline 19 & 0.8530 & -0.0164 \\
\hline 20 & 0.8465 & 0.0038 \\
\hline 21 & 0.8400 & -0.0049 \\
\hline 22 & 0.8335 & -0.0051 \\
\hline 23 & 0.8269 & -0.0062 \\
\hline 24 & 0.8202 & 0.0203 \\
\hline 25 & 0.8131 & -0.009 \\
\hline 26 & 0.8530 & - \\
\hline
\end{tabular}

Sample Acf and Pacf 


\section{Appendix 2}

Table 2: Average yearly exchange rate for Dollars in Naira (1992-2011).

\begin{tabular}{|c|c|}
\hline Year & Yearly average \\
\hline 1982 & 0.5464 \\
\hline 1983 & 0.6100 \\
\hline 1984 & 0.6729 \\
\hline 1985 & 0.7241 \\
\hline 1986 & 0.7649 \\
\hline 1987 & 0.8938 \\
\hline 1988 & 2.0206 \\
\hline 1989 & 4.0179 \\
\hline 1990 & 4.5367 \\
\hline 1991 & 7.3916 \\
\hline 1992 & 8.0378 \\
\hline 1993 & 9.9095 \\
\hline 1994 & 17.2984 \\
\hline 1995 & 22.0511 \\
\hline 1996 & 21.8861 \\
\hline 1997 & 21.8861 \\
\hline 1998 & 21.8861 \\
\hline 1999 & 21.8861 \\
\hline 2000 & 21.8861 \\
\hline 2001 & 92.6934 \\
\hline 2002 & 102.1052 \\
\hline 2003 & 111.9433 \\
\hline 2004 & 120.9702 \\
\hline 2005 & 129.3565 \\
\hline 2006 & 133.5004 \\
\hline 2007 & 132.1470 \\
\hline 2008 & 128.6516 \\
\hline 2009 & 125.8331 \\
\hline 2010 & 118.5669 \\
\hline 2011 & 148.9017 \\
\hline
\end{tabular}

Source: Data abstracted from Central bank of Nigeria (C.B.N) statistical bulletin in their official website (www.cbn.org). 
